\title{
Coregulation of Ethanol Discrimination by the Nucleus Accumbens and Amygdala
}

\author{
Joyce Besheer, Amy A. Cox, and Clyde W. Hodge
}

\begin{abstract}
Background: Activation of $\mathrm{GABA}_{\mathrm{A}}$ receptors in the amygdala or nucleus accumbens produces discriminative stimulus effects that substitute fully for those of systemically administered ethanol. This study was conducted to determine if $\mathrm{GABA}_{\mathrm{A}}$ receptors in the amygdala and nucleus accumbens interactively modulate ethanol discrimination.

Methods: Male Long-Evans rats were trained to discriminate between intraperitoneal injections of ethanol $(1 \mathrm{~g} / \mathrm{kg})$ and saline on a 2-lever drug discrimination task. The rats were then surgically implanted with bilateral injection cannulae aimed at the nucleus accumbens and the amygdala.

Results: Infusion of the $\mathrm{GABA}_{\mathrm{A}}$ agonist muscimol in the nucleus accumbens resulted in full substitution for systemically administered ethanol. Concurrent infusion of the $\mathrm{GABA}_{\mathrm{A}}$ antagonist bicuculline in the amygdala shifted the muscimol substitution curve in the nucleus accumbens 10 -fold to the right.

Conclusions: These results indicate that blockade of $\mathrm{GABA}_{\mathrm{A}}$ receptors in the amygdala significantly reduces the potency of the $\mathrm{GABA}_{\mathrm{A}}$ agonist in the nucleus accumbens. This suggests that the ethanol-like stimulus effects of $\mathrm{GABA}_{\mathrm{A}}$ receptor activation in the nucleus accumbens are modulated by $\mathrm{GABA}_{\mathrm{A}}$ receptor activity in the amygdala. These data support the hypothesis that the addictive stimulus properties of alcohol are mediated by GABAergic transmission in a neural circuit involving the amygdala and nucleus accumbens.
\end{abstract}

Key Words: Drug Discrimination, Bicuculline, GABA ${ }_{\mathrm{A}}$, Muscimol, Rat.

$\mathbf{S}^{\mathrm{E}}$ EVERAL OF ETHANOL'S effects on brain processes are mediated by changes in $\mathrm{GABA}_{\mathrm{A}}$ receptor function (Allan and Harris, 1987a,b; Ticku, 1990,1991). Acute ethanol administration enhances $\mathrm{Cl}^{-}$influx (Mehta and Ticku, 1988; Suzdak et al., 1986,1988) and potentiates GABA(Ticku, 1990) and muscimol-induced $\mathrm{Cl}^{-}$influx (Suzdak et al., 1986). $\mathrm{GABA}_{\mathrm{A}}$ receptor-mediated $\mathrm{Cl}^{-}$conductance is positively modulated at a GABA recognition site and also at allosteric sites that bind steroids, benzodiazepines, and barbiturates (Peters et al., 1988; Study and Barker, 1981).

In ethanol discrimination studies, in which animals are trained to discriminate ethanol from vehicle, positive modulators of $\mathrm{GABA}_{\mathrm{A}}$ receptors substitute for ethanol. For example, systemically administrated benzodiazepines or barbiturates substitute for ethanol (Barry, 1991; Hiltunen and Jarbe, 1986; Kline and Young, 1986; Kubena and Barry, 1969; Overton, 1977) and benzodiaz-

From the Bowles Center for Alcohol Studies, Department of Psychiatry, University of North Carolina at Chapel Hill, Chapel Hill, North Carolina.

Received for publication October 23, 2002; accepted December 17, 2002.

This work was supported by National Institute on Alcohol Abuse and Alcoholism Grant AA09981 and the Bowles Center for Alcohol Studies.

Reprint requests: Clyde W. Hodge, PhD, Bowles Center for Alcohol Studies, Thurston-Bowles Building; CB\#7178, University of North Carolina at Chapel Hill, Chapel Hill, North Carolina 27599; Fax: 919-966-5679; E-mail: chodge@med.unc.edu

Copyright () 2003 by the Research Society on Alcoholism.

DOI: 10.1097/01.ALC.0000057036.64169.C1 epines potentiate ethanol discrimination when coadministered with ethanol (Jarbe and McMillan, 1983). Neurosteroids with $\mathrm{GABA}_{\mathrm{A}}$ receptor-modulating properties such as allopregnanolone also substitute for ethanol (Bienkowski and Kostowski, 1997; Bowen et al., 1999a; Grant et al., 1996,1997) and potentiate ethanol discrimination (Bowen et al., 1999b).

The discriminative stimulus effects of ethanol are mediated by central nervous system mechanisms (Hodge, 1994), which include $\mathrm{GABA}_{\mathrm{A}}$ receptor activity in specific limbic brain regions (Hodge and Cox, 1998). For example, the $\mathrm{GABA}_{\mathrm{A}}$ agonist muscimol injected into the nucleus accumbens (Hodge and Aiken, 1996; Hodge and Cox, 1998) or amygdala (Hodge and Cox, 1998) of rats substitutes for ethanol. Moreover, the $\mathrm{GABA}_{\mathrm{A}}$ positive modulators pentobarbital and allopregnanolone both substitute for systemic ethanol when they are administered in the nucleus accumbens (Hodge et al., 2001b). However, direct stimulation of $\mathrm{GABA}_{\mathrm{A}}$ receptors in the prelimbic cortex (Hodge and Cox, 1998) or allosteric modulation in the hippocampus (Hodge and Cox, 1998) both fail to substitute for ethanol. These data suggest that $\mathrm{GABA}_{\mathrm{A}}$ receptors in the nucleus accumbens and amygdala may play a more influential role in ethanol discrimination than those in other brain regions.

Ethanol discrimination also appears to be mediated by connections among brain regions. Infusion of the noncompetitive N-methyl-D-aspartate (NMDA) antagonist MK 
801 in the nucleus accumbens or hippocampus substitutes for ethanol with equal potency and efficacy among brain regions (Hodge and Cox, 1998). However, coinfusion of a subthreshold dose of MK 801 in the hippocampus shifted the MK 801 substitution curve in the nucleus accumbens 10 -fold to the left, indicating interaction among NMDA receptors in these two brain regions (Hodge and Cox, 1998). Also, NMDA infusion in the hippocampus prevents ethanol substitution induced by MK 801 injection in the nucleus accumbens, which suggests that glutamate projections from the hippocampus to the accumbens influence ethanol discrimination (Hodge and Cox, 1998). Within the nucleus accumbens or amygdala, muscimol substitution for ethanol is potentiated by coinfusion of MK 801 indicating interactions among $\mathrm{GABA}_{\mathrm{A}}$ and NMDA neurotransmitter receptors in these brain regions (Hodge and Cox, 1998).

Given that $\mathrm{GABA}_{\mathrm{A}}$ activation in the amygdala or the nucleus accumbens substitutes for ethanol, there exists the possibility for interactions between these brain regions. Indeed, the presence of glutamatergic projections from the amygdala to the nucleus accumbens (Robinson and Beart, 1988) may mediate this interaction. For example, activation of $\mathrm{GABA}_{\mathrm{A}}$ receptors on glutamate projection neurons in the amygdala would result in decreased excitation in the accumbens, a property of the discriminative stimulus effects of ethanol (Hodge and Cox, 1998). This suggests that muscimol infusion in the amygdala may substitute for ethanol (Hodge and Cox, 1998) by reducing glutamate activity in the accumbens. Conversely, blockade of $\mathrm{GABA}_{\mathrm{A}}$ receptors on glutamate projection neurons in the amygdala might increase glutamate-induced excitation of the nucleus accumbens, which should inhibit ethanol substitution by GABAergics in this brain region. No studies have examined interactions between the amygdala and the nucleus accumbens in the discriminative stimulus effects of ethanol.

Therefore, the present experiment was designed as an initial examination of potential interactions between the amygdala and the nucleus accumbens in ethanol discrimination. In rats trained to discriminate ethanol $(1.0 \mathrm{~g} / \mathrm{kg})$ from vehicle, the $\mathrm{GABA}_{\mathrm{A}}$ agonist muscimol was microinjected into the nucleus accumbens alone and in conjunction with the $\mathrm{GABA}_{\mathrm{A}}$ antagonist bicuculline methobromide in the amygdala. Blockade of $\mathrm{GABA}_{\mathrm{A}}$ receptors in the amygdala altered the ability of muscimol in the nucleus accumbens to substitute for ethanol in a manner that is consistent with increased excitatory input to the nucleus accumbens from the amygdala.

\section{METHOD}

\section{Animals}

Twelve experimentally naive male Long-Evans rats (Charles River Laboratories, Wilmington, MA) were individually housed in Plexiglas cages. Body weights were maintained at approximately $320 \mathrm{~g}$ via food restriction; water was available continuously in the home cage. The colony room was maintained on a 12-hr light/dark cycle and experiments were conducted during the light portion of the cycle. All rats were weighed and inspected daily for general health.

\section{Apparatus}

Operant chambers $(31 \mathrm{~L} \times 32 \mathrm{H} \times 24 \mathrm{~W})$ located within soundattenuating cubicles with exhaust fans were used for discrimination sessions (Med Associates, Georgia, VT). On the right wall of the chambers were two levers. Responses on one of the levers activated a liquid dispenser centered between the levers that presented fluid in a 0.1-ml dipper cup for $4 \mathrm{sec}$ during each operation. The chambers were illuminated by an 8 -W light located on the left wall $28 \mathrm{~cm}$ above the dipper. The chambers were interfaced (Med Associates) to a computer that was programmed to control sessions and record data.

\section{Procedure}

Rats were handled and weighed daily for 1 week to allow habituation to the individual housing conditions and the laboratory. During this time food and water were available continuously. Once target body weight was reached, food restriction began and rats were allowed approximately 16 $\mathrm{g}$ /day. Rats were then trained to lever press on a fixed-ratio 1 (FR1) schedule of reinforcement. That is, a single lever press on either of the two levers resulted in presentation of $0.1 \mathrm{ml}$ of a liquid sucrose solution $(10 \%$ $\mathrm{w} / \mathrm{v})$. After 3 days, rats were trained to press either the right or the left lever during the 30-min daily sessions. The active lever was alternated each day (e.g., left or right) and responses on the inactive lever were recorded but did not result in any programmed consequence. During this training, the schedule of reinforcement was gradually increased to FR10 and all animals received an equal history with each lever at each FR value. Discrimination training began once responding on the FR10 schedule was stable ( $<10 \%$ daily variation in total number of responses).

Training sessions were conducted 5 days per week (M-F) during which ethanol $(1.0 \mathrm{~g} / \mathrm{kg})$ or saline was administered intraperitoneally (IP) prior to the start of the 15-min sessions. Immediately following the ethanol or saline injection, the rats were placed in the operant chambers for $10 \mathrm{~min}$ before the illumination of the house light and the extension of the levers into the chamber signaled the beginning of the session. Following ethanol injections, completion of 10 responses on the ethanol-appropriate lever resulted in the presentation of the sucrose solution. Similarly, following saline injections, completion of 10 responses on the saline-appropriate lever resulted in sucrose delivery. During both ethanol and saline sessions, responses on the inappropriate lever were recorded but produced no programmed consequences. The lever associated with ethanol or saline administration was randomly assigned and counterbalanced across animals. There were an equal number of saline and ethanol training days that varied on a double alternation schedule (ethanol, ethanol, saline, saline, and so on). The training sessions continued until the percentage of ethanol and saline appropriate lever press responses emitted prior to the first reinforcer, and during the entire session, exceeded $80 \%$ for 5 consecutive days. Once these criteria were met, rats underwent cannulae implantation surgery.

\section{Surgery}

Rats were anesthetized with pentobarbital $(60 \mathrm{mg} / \mathrm{kg}$, IP) and placed in a stereotaxic device (David Kopf Instruments, Tujunga, CA) with the incisor bar $3.3 \mathrm{~mm}$ below the horizontal plane. Guide cannulae (26-gauge stainless-steel tubing) were implanted bilaterally to terminate $1 \mathrm{~mm}$ dorsal to the nucleus accumbens and the amygdala. The cannulae were secured to the skull with dental cement and stainless-steel screws. Stylets were placed in the cannulae to prevent obstructions and infections. The stereotaxic coordinates (Paxinos and Watson, 1997) for cannulae placement were: nucleus accumbens $(+1.5 \mathrm{~mm} \mathrm{AP},+1.8 \mathrm{~mm} \mathrm{ML},-6.0 \mathrm{~mm} \mathrm{DV})$; amygdala ( $-2.5 \mathrm{~mm} \mathrm{AP,}+4.2 \mathrm{~mm} \mathrm{ML},-6.2 \mathrm{~mm} \mathrm{DV})$. Rats were allowed 1 week to recover from surgery before operant sessions resumed. 


\section{Substitution Testing: IP Ethanol}

After recovery from surgery, training sessions resumed until performance following IP injections of ethanol and saline again met the accuracy criteria. Once the criteria were reached, test sessions were conducted to determine an ethanol (0.1-1.5 $\mathrm{g} / \mathrm{kg}$, IP) substitution curve. Test sessions were identical to the training sessions except that they were $2 \mathrm{~min}$ in duration, completion of an FR10 on either lever resulted in sucrose delivery, and a novel dose of ethanol was administered during each test. These test sessions were interspersed with training sessions only if performance during the previous five training sessions met the accuracy criteria. If the criteria were not met, testing was delayed and training continued until response accuracy was greater than $80 \%$ for 5 consecutive days. After the IP ethanol substitution curve was determined, microinjection testing began.

\section{Substitution Testing: Microinjection of $G A B A_{A}$ Agonist and Antagonist}

Microinjection test sessions were interspersed with training sessions if performance during the previous 10 training sessions met the accuracy criteria. Unanesthetized rats were placed in a plastic tub $(27 \times 17 \times 12$ $\mathrm{cm})$ to minimize movement. Stylets were removed and the cannulae were swabbed with sterile physiologic saline. Bilateral injections in each brain region were performed simultaneously. Infusions were performed through 33-gauge stainless-steel hypodermic tubing lowered to $1 \mathrm{~mm}$ below the end of the guide cannulae. The pump delivered $0.5 \mu \mathrm{l} / \mathrm{side} / \mathrm{min}$ for a total volume of $0.5 \mu \mathrm{l} / \mathrm{side}$. Injectors remained in place for 30 additional seconds to allow drug diffusion. Rats were immediately administered IP saline and placed in the operant chambers. The beginning of test sessions was signaled by illumination of the house light and insertion of the response levers $10 \mathrm{~min}$ following placement in the chambers. Thus, discrimination testing occurred between 10.5 and 12.5 min postinfusion, which corresponds to a time when $>80 \%$ of infused muscimol remains within $1.0 \mathrm{~mm}$ of the brain injection sites (Edeline et al., 2002).

To control for procedural effects, sham injections were performed in combination with the training dose of ethanol $(1 \mathrm{~g} / \mathrm{kg})$ and saline. These injections were identical to the actual microinjections except that the injectors were of the same length as the guide cannulae to prevent brain penetration and although the pumps were operated, the syringes were not activated. After sham injections, intra-accumbens muscimol $(0.01,0.03$, and $0.1 \mu \mathrm{g} / \mu \mathrm{l}$ ) was tested for ethanol substitution in combination with ACSF vehicle in the amygdala. Higher doses of intra-accumbens muscimol $(0.1,0.3$, and $1.0 \mu \mathrm{g} / \mu \mathrm{l})$ were tested in combination with bicuculline (0.3 $\mu \mathrm{g} / \mu \mathrm{l})$ in the amygdala. Drugs and doses were administered in randomized order.

\section{Drugs}

Ethanol $(95 \% \mathrm{w} / \mathrm{v})$ was diluted in saline $(0.9 \%)$ to a concentration of $20 \% \mathrm{v} / \mathrm{v}$ and was administered IP in various volumes to obtain doses of 0.1 , $0.5,1.0,1.5 \mathrm{~g} / \mathrm{kg}$. Muscimol and bicuculline (Research Biochemicals International, Natick, MA) were dissolved in sterile-filtered artificial cerebrospinal fluid for central administration. All drug solutions were prepared immediately prior to each injection session. The $\mathrm{pH}$ of drug solutions was verified to be between 7.2 and 7.4.

\section{Histology}

Once the experiment was completed, rats were deeply anesthetized with pentobarbital and perfused transcardially with sodium phosphate buffer solution ( $\mathrm{pH} 7.5$ ) followed by $10 \%$ formaldehyde. Brains were extracted and stored in $10 \%$ formalin/30\% sucrose for at least 7 days, after which they were sliced into $60-\mu \mathrm{m}$ sections and stained with cresyl violet. Cannulae placement was verified using a standard light microscope (Bausch and Lomb) and only the data from rats with cannulae determined to be in the target brain regions were used in the analyses.

\section{Data Analyses}

The degree of ethanol substitution was expressed as the percentage of ethanol-appropriate lever presses upon delivery of the first reinforcer. As a measure of locomotor ability, response rate (responses/min) was analyzed for the entire session. Group averages for the saline and ethanol training sessions from 10 days immediately prior to the beginning of testing represented control performance for the effects of IP ethanol. Performance during sham injections (saline and ethanol) was used as a control for microinjection data. Complete substitution to the ethanol stimulus was defined as $>80 \%$ choice of the ethanol lever upon completion of the first FR10 during test sessions. Degree of ethanol substitution and response rate data during test sessions were analyzed by repeatedmeasures analysis of variance (ANOVA). When test doses of drugs produced significant main effects, post hoc comparisons against the saline control were conducted with Dunnett's method. ED50 values for the dose effects were determined by log-dose probit analysis where appropriate. Data were used only from animals determined histologically to have bilateral injector placement in both target brain regions and if performance during training sessions continued to meet the accuracy criteria. All data are presented as mean $( \pm$ SEM).

\section{RESULTS}

\section{Histology}

Histologic examination showed that 11 of the 12 rats received bilateral injections in the nucleus accumbens and the amygdala. Data from one subject was excluded from the analyses due to unilateral placement in the nucleus accumbens. All data represent the average performance of 11 subjects.

\section{Substitution Testing: IP Ethanol}

An average of $42.5( \pm 1.8)$ training sessions was required for behavior to reach the acquisition criteria with a range of 34 to 56 sessions. Performance during postsurgery ethanol substitution test sessions is shown in Fig. 1. The percentage of ethanol-lever responding on completion of the first FR10 (Fig. 1A) was approximately 90\% during ethanol control sessions and less than $10 \%$ during saline control sessions indicating that the procedures established reliable stimulus control. The percentage of ethanol-appropriate responses increased significantly as a function of ethanol test dose $[F(4,40)=73.16, p<0.001]$. Both the 1.0 and 1.5 $\mathrm{g} / \mathrm{kg}$ test doses of ethanol substituted fully for the $1.0 \mathrm{~g} / \mathrm{kg}$ training dose (Fig. 1A). Dose-dependent substitution by IP ethanol was observed in 10 of 11 animals tested with an ED50 value of $0.63 \mathrm{~g} / \mathrm{kg}$ ( \pm 0.07$)$. The training dose (1.0 $\mathrm{g} / \mathrm{kg}$ ) had no effect on response rate, however a significant reduction in response rate was observed $[F(4,40)=4.17, p$ $=0.006]$ due to reduction at the highest ethanol test dose (Fig. 1B).

\section{Substitution Testing: Microinjection of $G A B A_{A}$ Agonist and Antagonist}

Panel A of Fig. 2 shows the data from the substitution tests following infusion of muscimol in the nucleus accumbens and with concurrent infusion of bicuculline in the amygdala. Muscimol $(0.01-0.1 \mu \mathrm{g} / \mu \mathrm{l})$ injected into the ac- 

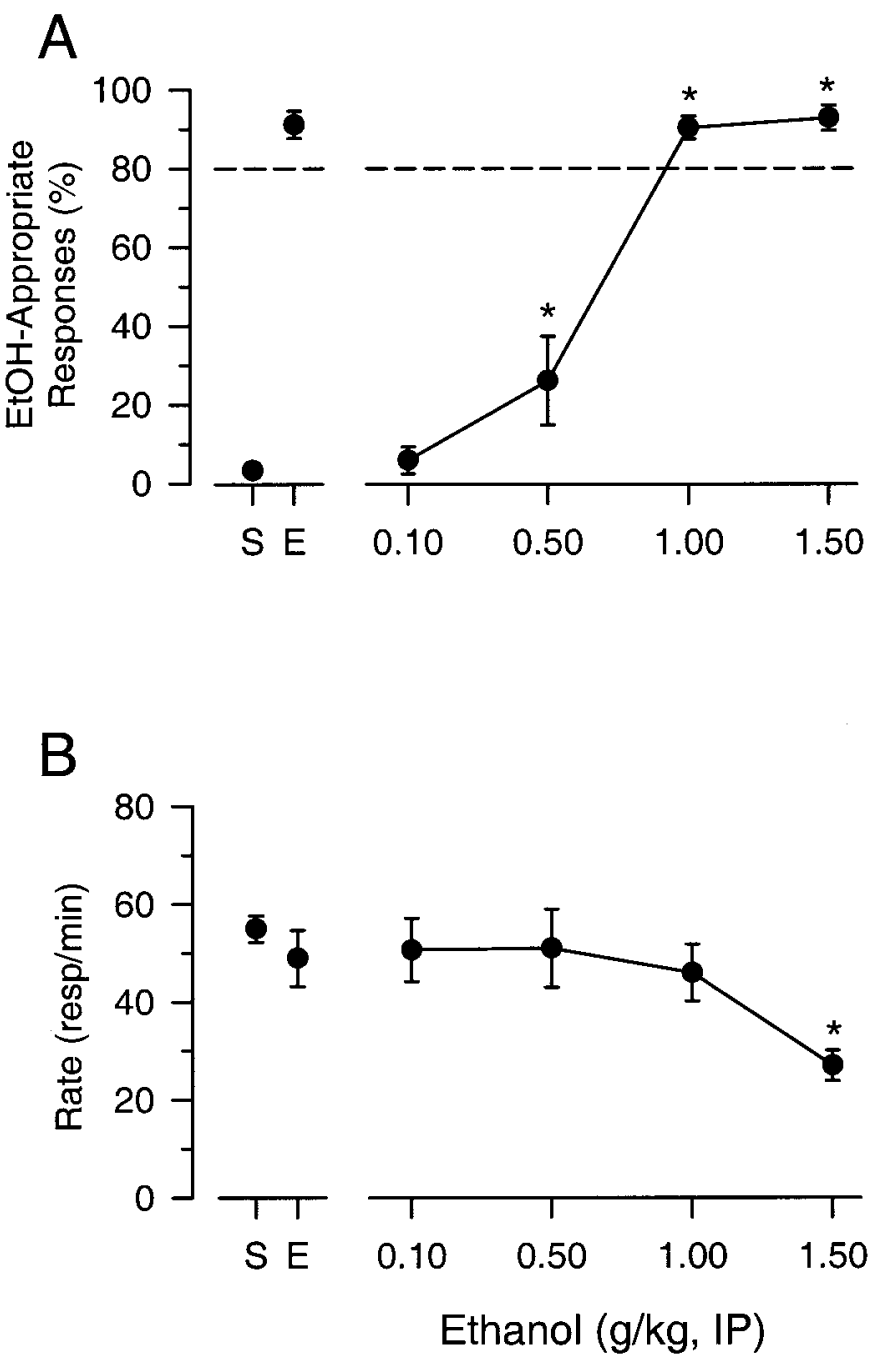

Fig. 1. Panel A. Mean ( \pm SEM) percentage of ethanol-appropriate responding upon completion of the first FR10 at each ethanol dose tested. Panel B. Mean ( \pm SEM) total session response rate at each ethanol dose tested. Data points to the left of the x-axis break represent performance on saline (S) and ethanol (E) performance during the last 10 days prior to testing. Data points to the right of the $\mathrm{x}$-axis break represent test session performance following IP ethanol administration. The horizontal dashed line $(>80 \%)$ represents full substitution for the discriminative stimulus effects of ethanol $(1.0 \mathrm{~g} / \mathrm{kg}, \mathrm{IP}) .{ }^{*}$ Indicates significant difference from $\mathrm{S}$ control (Dunnett, $p<0.05$ ).

cumbens produced dose-dependent substitution for systemic ethanol $[F(3,30)=36.96, p<0.001]$. Full substitution by muscimol $(0.1 \mu \mathrm{g} / \mu \mathrm{l})$ was observed in 10 of the 11 animals tested with an ED50 of $0.053( \pm 0.007 \mu \mathrm{g})$. Dosedependent substitution of higher doses of muscimol (0.1-1 $\mu \mathrm{g} / \mu \mathrm{l})$ was also observed with simultaneous injection of bicuculline $(0.03 \mu \mathrm{g} / \mu \mathrm{l})$ in the amygdala $[F(3,30)=17.59$, $p<0.001]$. Full substitution by muscimol $(1.0 \mu \mathrm{g} / \mu \mathrm{l})$ was observed in 10 of the 11 rats tested with an ED50 of 0.504 $( \pm 0.087 \mu \mathrm{g})$. The ED50 for one rat could not be calculated and thus the average ED50 represents the values of 10 rats. Comparison of mean ED50 values for intra-accumbens muscimol alone and after simultaneous infusion of bicuculline in the amygdala demonstrated a 10-fold rightward shift
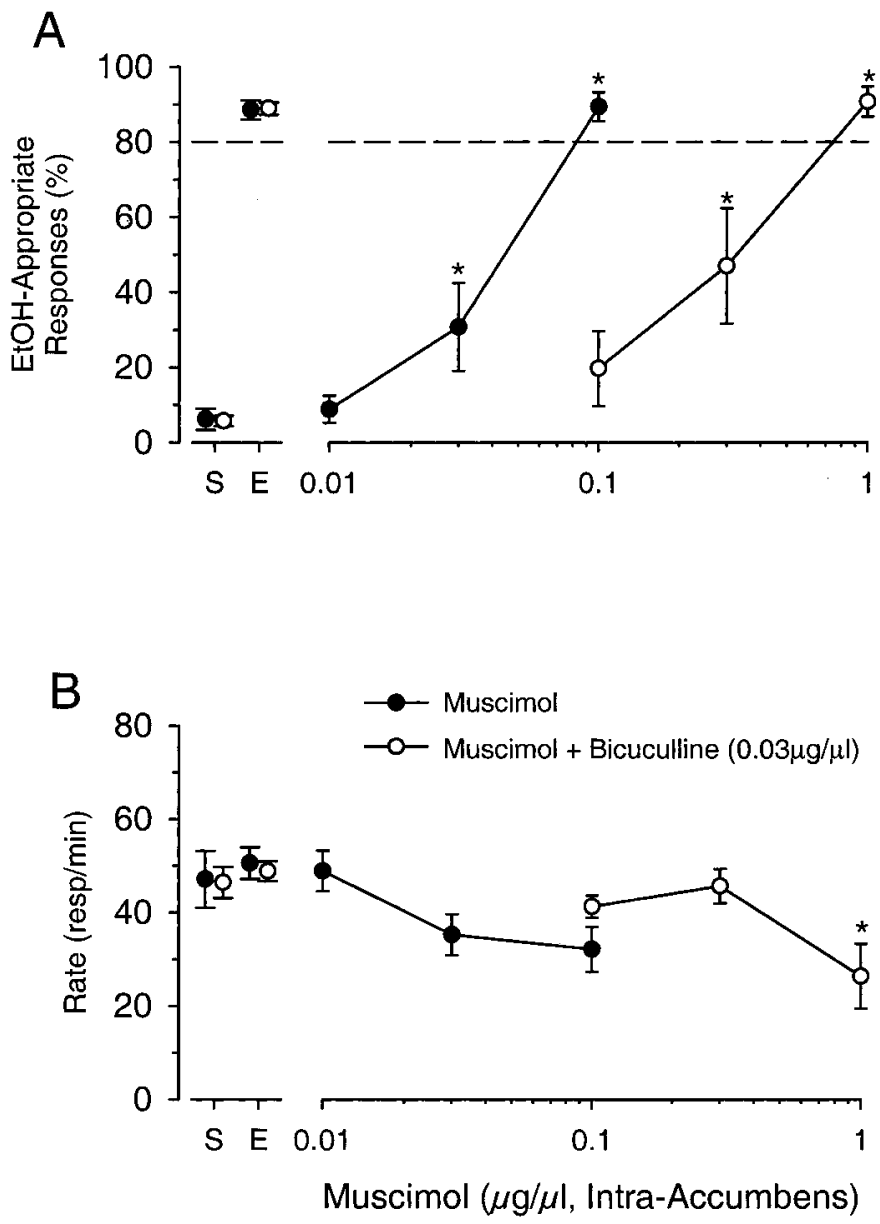

Fig. 2. Panel A. Mean ( \pm SEM) percentage of responses that occurred on the ethanol-appropriate lever upon completion of the first FR10 at each muscimol dose tested. Panel B. Mean ( \pm SEM) total session response rate at each muscimol dose tested. Muscimol was either administered alone ([circf]) in the nucleus accumbens or in combination with $0.03 \mu \mathrm{g} / \mu \mathrm{l}$ bicuculline ([circo]) infused into the amygdala. Data points to the left of the of the $x$-axis break represent control saline $(\mathrm{S})$ or ethanol $(E)$ performance. The horizontal dashed line $(>80 \%)$ represents full substitution for the discriminative stimulus effects of ethanol $(1.0 \mathrm{~g} / \mathrm{kg}, \mathrm{IP})$. * Indicates significant difference from $\mathrm{S}$ control (Dunnett, $p<0.05$ ).

in the muscimol substitution curve $[t(9)=5.244, p=$ 0.0005].

Response rates for the substitution tests are shown in Panel B of Fig. 2. There was no significant change in response rate following muscimol infusion in the nucleus accumbens alone $[F(3,30)=2.68, p=0.06]$. However, simultaneous infusion of bicuculline affected response rate significantly $[F(3,30)=4.06, p=0.02]$ at the highest dose of muscimol $(1.0 \mu \mathrm{g} / \mu \mathrm{l})$ tested.

\section{DISCUSSION}

GABA is the primary inhibitory neurotransmitter in the mammalian central nervous system. The discriminative stimulus effects of ethanol, which have an inhibitory/sedative component, are partly mediated by $\mathrm{GABA}_{\mathrm{A}}$ receptors (Grant, 1994 review). GABA $_{\mathrm{A}}$ receptors in the nucleus accumbens or in the amygdala both contribute to the dis- 
criminative stimulus properties of ethanol (Hodge and Cox, 1998). The purpose of this study was to examine a potential interaction between $\mathrm{GABA}_{\mathrm{A}}$ receptors in the nucleus accumbens and the amygdala in ethanol discrimination.

Previous studies have shown that microinjection of the direct $\mathrm{GABA}_{\mathrm{A}}$ agonist muscimol into the nucleus accumbens or amygdala is sufficient to produce stimulus effects that correspond to those of systemically administered ethanol (Hodge and Aiken, 1996). Similarly, allosteric positive modulation of $\mathrm{GABA}_{\mathrm{A}}$ receptors in the nucleus accumbens by pentobarbital or allopregnanolone results in full substitution for ethanol (Hodge et al., 2001b). In agreement with these findings, the present study showed that muscimol infusion in the nucleus accumbens substituted fully for systemic ethanol. The results of this study also showed that blockade of $\mathrm{GABA}_{\mathrm{A}}$ receptors in the amygdala by bicuculline shifted the muscimol substitution curve 10 -fold to the right. This shift in the muscimol substitution curve was accompanied by a significant reduction in response rate, similar to that observed during the ethanol substitution test at the $1.5 \mathrm{~g} / \mathrm{kg}$ ethanol dose. This data pattern is consistent with the known sedative effects of GABAergic compounds (Plaznik et al., 1990) and is also a stimulus property of higher ethanol doses (Grant, 1994). Importantly, these data provide the first evidence that $\mathrm{GABA}_{\mathrm{A}}$ receptors in the amygdala and nucleus accumbens may interactively modulate the stimulus effects of ethanol.

One mechanism by which intra-amygdala bicuculline may have reduced the effects of muscimol in the nucleus accumbens is through disinhibition of excitatory projection neurons. Indeed, there are amygdala-accumbens glutamatergic projections (Robinson and Beart, 1988) which are under strong tonic inhibition by intrinsic GABAergic neurons (Rammes et al., 2000,2001; Sun et al., 1994). Therefore, disruption of intrinsic GABAergic transmission alters the functioning of postsynaptic neurons resulting in disinhibition (Rainnie et al., 1991). For example, application of bicuculline, the $\mathrm{GABA}_{\mathrm{A}}$ antagonist, in the amygdala enhances the intensity and the area of signal propagation (Wang et al., 2001). That is, disinhibition is produced and previously silent areas of the amygdala nuclei are activated. Furthermore, Wang et al. (2001) suggest that a product of this bicuculline-induced disinhibition is an enhancement of glutamate release. We showed previously that increased glutamatergic input to the nucleus accumbens interferes with the discriminative stimulus effects of ethanol (Hodge and Cox, 1998). Therefore, bicuculline injection in the amygdala might have reduced tonic GABAergic inhibition of glutamate projection neurons that synapse in the accumbens, which would require higher doses of muscimol to substitute for ethanol.

Another plausible explanation related to bicucullineinduced disinhibition in the amygdala involves glutamatergic interactions between the amygdala and the hippocampus (Kaura et al., 1995; Minamoto et al., 1992; Packard and Chen, 1999). These interactions may be mediated by direct amygdalo-hippocampal (Saunders and Rosene, 1988) or amygdalo-entorhino-hippocampal projections (Colino and Fernandez de Molina, 1986). NMDA receptors in the hippocampus have also been implicated in mediating the discriminative stimulus effects of ethanol. Specifically, blockade of NMDA receptors by MK-801 in the hippocampus substitutes for ethanol (Hodge and Cox, 1998). Further, a relationship between the hippocampus and the nucleus accumbens has also been implicated in mediating the stimulus effects of ethanol. That is, concurrent blockade of NMDA receptors in the hippocampus and the nucleus accumbens results in a leftward shift of the MK-801 substitution curve. Also, NMDA administered in the hippocampus with concurrent NMDA blockade in the nucleus accumbens blocks MK-801 substitution in the accumbens. These findings suggest a role for glutamatergic hippocampus-accumbens projections in ethanol discrimination. Thus, disinhibition produced in the amygdala by administration of bicuculline could induce excitation in the hippocampus directly by activation of the amygdalohippocampal projection or indirectly by activation of the amygdalo-entorhino-hippocampal projection (Berretta et al., 2001). As reported by Hodge and Cox (1998) blockade of NMDA receptors in the hippocampus produces ethanollike stimulus effects, suggesting that excitation in the hippocampus would not substitute for ethanol. Consequently, given the relationship between the hippocampus and nucleus accumbens concurrent activation of $\mathrm{GABA}_{\mathrm{A}}$ receptors by administration of higher doses of muscimol in the nucleus accumbens would presumably reduce excitation and result in ethanol substitution.

Interestingly, the results of the present study are consistent with evidence showing that $\mathrm{GABA}_{\mathrm{A}}$ receptors in the nucleus accumbens or amygdala influence ethanol selfadministration (Hodge et al., 1995; Hyytia and Koob, 1995). For instance, muscimol infusion in the nucleus accumbens reduces ethanol-reinforced responding by producing early termination, which is consistent with muscimol substituting for self-administered ethanol (Hodge et al., 1995). Accordingly, we have shown that the discriminative stimulus effects of self-administered ethanol are enhanced by $\mathrm{GABA}_{\mathrm{A}}$ receptor activation (Hodge et al., 2001a). Other data indicate that intra-amygdala infusion of the $\mathrm{GABA}_{\mathrm{A}}$ receptor antagonist SR 95531 decreased ethanol selfadministration (Hyytia and Koob, 1995). This evidence indicates that there is overlap between the brain regions and transmitter systems that mediate ethanol selfadministration and discrimination. Importantly, the implication of this observation is that the termination of ethanol self-administration, which becomes dysregulated in addiction, may be influenced by GABA-mediated stimulus effects of self-administered ethanol in the nucleus accumbens or amygdala.

In conclusion, the results of this study are consistent with previous work (Hodge and Aiken, 1996; Hodge and Cox, 1998) showing that $\mathrm{GABA}_{\mathrm{A}}$ receptors in the nucleus ac- 
cumbens or amygdala mediate the discriminative stimulus effects of systemically administered ethanol. The major finding from this study is that blockade of $\mathrm{GABA}_{\mathrm{A}}$ receptors in the amygdala reduced the ethanol-like stimulus effects of $\mathrm{GABA}_{\mathrm{A}}$ receptor activation in the nucleus accumbens. These data provide further support for the hypothesis that the addictive properties of alcohol are mediated by GABAergic transmission in specific limbic brain regions.

\section{REFERENCES}

Allan AM, Harris RA (1987a) Involvement of neuronal chloride channels in ethanol intoxication, tolerance, and dependence. Recent Dev Alcohol 5:313-325.

Allan AM, Harris RA (1987b) Acute and chronic ethanol treatments alter GABA receptor-operated chloride channels. Pharmacol Biochem Behav 27:665-670.

Barry H III (1991) Distinctive discriminative effects of ethanol. NIDA Res Monogr (116):131-144.

Berretta S, Munno DW, Benes FM (2001) Amygdalar activation alters the hippocampal GABA system: "Partial" modelling for postmortem changes in schizophrenia. J Comp Neurol 431:129-138.

Bienkowski P, Kostowski W (1997) Discriminative stimulus properties of ethanol in the rat: Effects of neurosteroids and picrotoxin. Brain Res 753:348-352.

Bowen CA, Purdy RH, Grant KA (1999a) Ethanol-like discriminative stimulus effects of endogenous neuroactive steroids: Effect of ethanol training dose and dosing procedure. J Pharmacol Exp Ther 289:405411.

Bowen CA, Purdy RH, Grant KA (1999b) An investigation of endogenous neuroactive steroid-induced modulation of ethanol's discriminative stimulus effects. Behav Pharmacol 10:297-311.

Colino A, Fernandez de Molina A (1986) Electrical activity generated in subicular and entorhinal cortices after electrical stimulation of the lateral and basolateral amygdala of the rat. Neuroscience 19:573-580.

Edeline JM, Hars B, Hennevin E, Cotillon N (2002) Muscimol diffusion after intracerebral microinjections: A reevaluation based on electrophysiological and autoradiographic quantifications. Neurobiol Learn Mem 78:100-124.

Grant KA (1994) Emerging neurochemical concepts in the actions of ethanol at ligand-gated ion channels. Behav Pharmacol 5:383-404.

Grant KA, Azarov A, Bowen CA, Mirkis S, Purdy RH (1996) Ethanol-like discriminative stimulus effects of the neurosteroid 3 alpha-hydroxy- 5 alpha-pregnan-20-one in female Macaca fascicularis monkeys. Psychopharmacology (Berl) 124:340-346.

Grant KA, Azarov A, Shively CA, Purdy RH (1997) Discriminative stimulus effects of ethanol and 3 alpha-hydroxy-5 alpha-pregnan-20-one in relation to menstrual cycle phase in cynomolgus monkeys (Macaca fascicularis). Psychopharmacology (Berl) 130:59-68.

Hiltunen AJ, Jarbe TU (1986) Discrimination of Ro 11-6896, chlordiazepoxide and ethanol in gerbils: Generalization and antagonism tests. Psychopharmacology (Berl) 89:284-290.

Hodge CW (1994) Comparison of the discriminative stimulus function of ethanol following intracranial and systemic administration: Evidence of a central mechanism. Pharmacol Biochem Behav 47:743-747.

Hodge CW, Aiken AS (1996) Discriminative stimulus function of ethanol: Role of GABAA receptors in the nucleus accumbens. Alcohol Clin Exp Res 20:1221-1228.

Hodge CW, Chappelle AM, Samson HH (1995) GABAergic transmission in the nucleus accumbens is involved in the termination of ethanol self-administration in rats. Alcohol Clin Exp Res 19:1486-1493.

Hodge CW, Cox AA (1998) The discriminative stimulus effects of ethanol are mediated by NMDA and GABA(A) receptors in specific limbic brain regions. Psychopharmacology (Berl) 139:95-107.
Hodge CW, Cox AA, Bratt AM, Camarini R, Iller K, Kelley SP, Mehmert KK, Nannini MA, Olive MF (2001a) The discriminative stimulus properties of self-administered ethanol are mediated by GABA(A) and NMDA receptors in rats. Psychopharmacology (Berl) 154:13-22.

Hodge CW, Nannini MA, Olive MF, Kelley SP, Mehmert KK (2001b) Allopregnanolone and pentobarbital infused into the nucleus accumbens substitute for the discriminative stimulus effects of ethanol. Alcohol Clin Exp Res 25:1441-1447.

Hyytia P, Koob GF (1995) GABAA receptor antagonism in the extended amygdala decreases ethanol self-administration in rats. Eur J Pharmacol 283:151-159.

Jarbe TU, McMillan DE (1983) Interaction of the discriminative stimulus properties of diazepam and ethanol in pigeons. Pharmacol Biochem Behav 18:73-80.

Kaura S, Bradford HF, Young AM, Croucher MJ, Hughes PD (1995) Effect of amygdaloid kindling on the content and release of amino acids from the amygdaloid complex: In vivo and in vitro studies. J Neurochem 65:1240-1249.

Kline FS, Young AM (1986) Differential modification of pentobarbital stimulus control by d-amphetamine and ethanol. Pharmacol Biochem Behav 24:1305-1313.

Kubena RK, Barry H III (1969) Generalization by rats of alcohol and atropine stimulus characteristics to other drugs. Psychopharmacologia 15:196-206.

Mehta AK, Ticku MK (1988) Ethanol potentiation of GABAergic transmission in cultured spinal cord neurons involves gamma-aminobutyric acid A-gated chloride channels. J Pharmacol Exp Ther 246:558-564.

Minamoto Y, Itano T, Tokuda M, Matsui H, Janjua NA, Hosokawa K, Okada Y, Murakami TH, Negi T, Hatase O (1992) In vivo microdialysis of amino acid neurotransmitters in the hippocampus in amygdaloid kindled rat. Brain Res 573:345-348.

Overton DA (1977) Comparison of ethanol, pentobarbital, and phenobarbital using drug vs. drug discrimination training. Psychopharmacology (Berl) 53:195-199.

Packard MG, Chen SA (1999) The basolateral amygdala is a cofactor in memory enhancement produced by intrahippocampal glutamate injections. Psychobiology 27:377-385.

Paxinos G, Watson C (1997) The Rat Brain in Stereotaxic Coordinates. Academic Press, San Diego.

Peters JA, Kirkness EF, Callachan H, Lambert JJ, Turner AJ (1988) Modulation of the GABAA receptor by depressant barbiturates and pregnane steroids. Br J Pharmacol 94:1257-1269.

Plaznik A, Stefanski R, Kostowski W (1990) GABAergic mechanisms in the nucleus accumbens septi regulating rat motor activity: The effect of chronic treatment with desipramine. Pharmacol Biochem Behav 36: 501-506.

Rainnie DG, Asprodini EK , Shinnick-Gallagher P (1991) Excitatory transmission in the basolateral amygdala. J Neurophysiol 66:986-998.

Rammes G, Eder M, Dodt HU, Kochs E, Zieglgansberger W (2001) Long-term depression in the basolateral amygdala of the mouse involves the activation of interneurons. Neuroscience 107:85-97.

Rammes G, Steckler T, Kresse A, Schutz G, Zieglgansberger W, Lutz B (2000) Synaptic plasticity in the basolateral amygdala in transgenic mice expressing dominant-negative cAMP response element-binding protein (CREB) in forebrain. Eur J Neurosci 12:2534-2546.

Robinson TG, Beart PM (1988) Excitant amino acid projections from rat amygdala and thalamus to nucleus accumbens. Brain Res Bull 20:467471.

Saunders RC, Rosene DL (1988) A comparison of the efferents of the amygdala and the hippocampal formation in the rhesus monkey. I. Convergence in the entorhinal, prorhinal, and perirhinal cortices. J Comp Neurol 271:153-184.

Study RE, Barker JL (1981) Diazepam and (-)pentobarbital: fluctuation analysis reveals different mechanisms for potentiation of gammaaminobutyric acid responses in cultured central neurons. Proc Natl Acad Sci USA 78:7180-7184. 
Sun N, Yi H, Cassell MD (1994) Evidence for a GABAergic interface between cortical afferents and brainstem projection neurons in the rat central extended amygdala. J Comp Neurol 340:43-64.

Suzdak PD, Schwartz RD, Skolnick P, Paul SM (1986) Ethanol stimulates gamma-aminobutyric acid receptor-mediated chloride transport in rat brain synaptoneurosomes. Proc Natl Acad Sci USA 83:4071-4075.

Suzdak PD, Schwartz RD, Skolnick P, Paul SM (1988) Alcohols stimulate gamma-aminobutyric acid receptor-mediated chloride uptake in brain vesicles: Correlation with intoxication potency. Brain Res 444:340-345.

Ticku MK (1990) Alcohol and GABA-benzodiazepine receptor function. Ann Med 22:241-246.

Ticku MK (1991) Ethanol interactions at the gamma-aminobutyric acid receptor complex. Ann N Y Acad Sci 625:136-144.

Wang C, Wilson WA, Moore SD (2001) Role of NMDA, non-NMDA, and GABA receptors in signal propagation in the amygdala formation. J Neurophysiol 86:1422-1429. 